\title{
90 CREATING SACRED SPACE FOR DYING: THE CHRYSALIS
} ROOM

Loretta Downs ${ }^{1}$ Chrysalis End-Of-Life Inspirations

10.1136/bmjspcare-2012-000250.87

The environment in which an experience occurs impacts the quality of that experience.

Hospitals and nursing homes are the locations for $75 \%$ of deaths in America, contrary to the surveyed preference that $80 \%$ of us want to die at home.

Institutions need to provide sacred space in the form of a private room(s) designated for the purpose of keeping vigil with the dying during the fi nal, most sacred transformation of life: a Chrysalis Room.

Death at home means a familiar environment fi lled with personal possessions and loved ones caring for the person dying. It means autonomy, privacy, comfort, quiet, control, and dignity. These qualities of home create the opportunity to care for each other, share stories, to make meaning of a life, to do the spiritual, emotional and psychological work of preparing for death. A chrysalis room in a nursing home or hospital is a quiet, comfortable, spacious, esthetic space designated for a dying person, in the care of hospice, to be supported through the final days of life. Family can be present and comfortable 24 hours. In a nursing home, the staff and other residents become family to each other. They are invited to be part of the vigil. Rituals are performed. Those who have been able to keep vigil in such sacred space report a peaceful experience, feelings of sorrow rather than painful emotions, and satisfaction for having been able to be there with one they love. 